\title{
Impact of Excessive Weight Loss on Cardiovascular Risk After Two Years of Bariatric Surgery
}

\section{FLAVIANA FREITAS PEDRON ( $\square$ flapedron@gmail.com )}

Universidade Franciscana - UFN

Glauco da Costa Alvarez

Universidade Federal de Santa Maria

\section{Luciana Dapieve Patias}

University of Santa Cruz do Sul

\section{Ana Cristina de Assunção Machado}

Universidade Federal de Santa Maria

Lidiany Oliveira de Lima

Universidade Franciscana - UFN

Deise Silva de Moura

Pontifical Catholic University of Rio Grande do Sul

\section{Aline Calcing}

Universidade Franciscana - UFN

Cristina Machado Bragança de Moraes

Universidade Franciscana - UFN

\section{Research Article}

Keywords: Obesity, Dyslipidemia, Weight loss percentage, Gastric Bypass

Posted Date: April 8th, 2021

DOI: https://doi.org/10.21203/rs.3.rs-350367/v1

License: (c) (i) This work is licensed under a Creative Commons Attribution 4.0 International License.

Read Full License 


\title{
IMPACT OF EXCESSIVE WEIGHT LOSS ON CARDIOVASCULAR RISK AFTER TWO YEARS OF BARIATRIC SURGERY
}

\section{CARDIOVASCULAR RISK AND BARIATRIC SURGERY}

\author{
Flaviana Freitas Pedron ${ }^{1 *+}$, Glauco da Costa Alvarez ${ }^{2+}$, Luciana Dapieve Patias ${ }^{3+}$, Ana \\ Cristina de Assunção Machado ${ }^{4+}$, Lidiany Oliveira de Lima ${ }^{5+}$, Deise Silva de Moura6+, \\ Aline Calcing ${ }^{7+}$,Cristina Machado Bragança de Moraes $^{8+}$ \\ 1*+ Universidade Franciscana - UFN, Santa Maria, RS, 97050-420 - Brasil - (flapedron@gmail.com) \\ 2+ Universidade Federal de Santa Maria - UFSM, Santa Maria, RS, 97050-600 - Brasil, \\ (Glaucoalvarez@terra.com.br) \\ 3+ Universidade de Santa Cruz do Sul - UNISC, Santa Cruz do Sul, RS, 96816-501 - Brasil, \\ (lu_patias@yahoo.com.br) \\ 4+ Universidade Federal de Santa Maria - UFSM, UFSM, Santa Maria, RS, 97050-600 - Brasil, \\ (Anacris@clinicadrglaucoalvarez.com.br) \\ 5+Universidade Franciscana - UFN, Santa Maria, RS, 97010-030 - Brasil - (lidiany.lima@ufn.edu.br) \\ ${ }^{6+}$ Pontifícia Universidade Católica do Rio Grande do Sul - PUCRS, Porto Alegre, RS, 90619-900 - Brasil, \\ (deisinhamoura@hotmail.com) \\ 7+Universidade Franciscana - UFN, Santa Maria, RS, 97010-030 - Brasil - (aline.calcing@ hotmail.com) \\ ${ }^{8+}$ Universidade Franciscana - UFN, Santa Maria, RS, 97010-030 - Brasil- (c_bmoraes @ yahoo.com.br)
}

\begin{abstract}
Overweightness is related to a high incidence of dyslipidemia, being considered a risk factor for cardiovascular diseases. Objective: Analysis of the effect of weight loss in reducing type 2 diabetes mellitus and cardiovascular risk 2 years after Roux-en- $Y$ gastric bypass. Methods: A retrospective study with patients who underwent Roux-en-Y gastric bypass involving accessing the database of an Obesity Surgery Clinic from March 2018 to March 2019. Male and female patients, aged 18 and over, who underwent bariatric surgery from March 2014 to March 2016 were analyzed. The following data were obtained from the medical records of patients: body weight, height, age, sex, glucose and glycated hemoglobin (HbA1C) after 24 months of surgery. Results: In total, 351 patients were studied, $80.9 \%$ of whom were female. There was a reduction in weight and in the
\end{abstract}


concentrations of all biochemical parameters, except HDLc, along with a decrease in the frequency of dyslipidemia and cardiovascular risk 24 months after surgery. When comparing variations between 6 and 12 months, only group 1 reduced $\mathrm{Hb} 1 \mathrm{Ac}$ and decreased CVR. There was a significant reduction in the level of glucose in group $1(\mathrm{p}=$ 0.036) at T4 (18 months) and T5 (24 months). Conclusion: The positive impact determined by bariatric surgery on weight loss was shown to be effective in improving the dyslipidemic profile, reducing morbidities associated with obesity and, consequently, reducing CVR after 24 months. Keywords: Obesity, Dyslipidemia, Weight loss percentage, Gastric Bypass.

\section{Abbre viations}

CVRFs Cardiovascular risk factors

T2DM Type 2 diabetes mellitus

SAH Arterial hypertension

BS Bariatric surgery

BMI Body mass index

EWL Excess weight loss

CVR Cardiovascular risk

HDL High density lipoproteins

LDL Low density lipoproteins

Hb1Ac Glycated hemoglobin

OAGB One anastomosis gastric bypass

\section{Introduction}

Obesity is a public health problem due to its increasing prevalence and high mortality rate. It also determines an increase in the frequency of chronic diseases [1], which further intensifies morbimortality in super-obese patients [2]. These diseases include those 
considered to be cardiovascular risk factors (CVRFs) such as systemic arterial hypertension (SAH), type 2 diabetes mellitus (T2DM) and dyslipidemia [3-4]. The obesity treatment involves drug and nutritional therapy, along with physical activity; however, these methods do not produce satisfactory results in the most severe cases, with $95 \%$ of individuals returning to their initial weight within two years [5-6]. The frustration of super-obese patients with the slow advances in conservative treatment motivates them to go through bariatric surgery (BS) due to its speed and effectiveness in the treatment of obesity. Patients who are suitable for bariatric surgery are those with clinical treatment failure and with a body mass index (BMI) above $35 \mathrm{~kg} / \mathrm{m}^{2}$ and associated comorbidities, or patients with a BMI $>40 \mathrm{~kg} / \mathrm{m}^{2}$. The health effects of bariatric surgery are satisfactory in the quality of life of patients, in addition to improvements in health conditions related to obesity and pre-existing comorbidities (glycemic levels, hypertension, 2 diabetes mellitus, hepatic steatosis, sleep apnea and reflux) [7-9]. Bariatric surgery has been used as a treatment for the super-obese patients and is an effective and lasting intervention, showing therapeutic success in relation to excess weight loss (\% EWL), in addition to a substantial improvement in comorbidities [10-11]. A meta-analysis with 134 studies involving 22,000 obese individuals has showed that gastric bypass determines, on average, a $61 \%$ reduction in EWL, $39.7 \mathrm{~kg}$ reduction in body weight, $13.2 \mathrm{kgm}^{2}$ reduction in BMI and a significant improvement or resolution of comorbidities [12]. The highest excess weight loss and the most beneficial effect on comorbidities occur approximately one year after surgery, remaining in most patients [13-14]. Much of this effect, however, can already be seen within the first six months [13]. Thus, understanding the anthropometric profile and the comorbidities of patients undergoing bariatric surgery is essential to measure the risks related to the morbimortality of the surgery and to provide resources, special care and postoperative support [15]. Considering this growing number 
of obesity cases in the population worldwide and the consequent increase in the number of bariatric surgeries, this study aims to evaluate the effect of excess weight loss in the solution of 2 diabetes mellitus and CVR), using the Framingham Risk Score [16] two years after bariatric surgery.

\section{Results}

The number of evaluated patients who underwent Gastric Bypass was 351. The sample of this study consisted of 284 women (80.9\%) and 67 men (19.1\%), aged between 20 and 70 years old and with an average age of $42.1 \pm 11.2$ years. The mean and standard deviation values of the continuous variables in the preoperative evaluation such as body weight and BMI are described in Table 1 according to the criteria established by the Ministry of Health [19] for the indication of Roux-en-Y gastric bypass. All 351 individuals underwent one anastomosis gastric bypass (OAGB), thus constituting the study sample.

Table 1. Demographic and anthropometric data of patients undergoing OAGB.

\begin{tabular}{lc}
\hline Characteristic & $\mathbf{n}=\mathbf{3 5 1}$ \\
\hline Age (years) - mean \pm SD & $42.1 \pm 11.2$ \\
Gender $-\mathbf{n}(\boldsymbol{\%})$ & $284(80.9)$ \\
Female & $67(19.1)$ \\
Male & \\
Weight $(\mathbf{k g})$ & $115.8 \pm 19.3$ \\
Pre-surgical - mean \pm SD & $55.9 \pm 7.2$ \\
Final $(24$ months) - mean \pm SD & \\
BMI (kg/m²) & $42.6 \pm 4.6$ \\
Pre-surgical - mean \pm SD & $26.7 \pm 4.5$ \\
Final $(24$ months) - mean \pm SD & $73.3 \pm 0.8$ \\
\% EWL - mean \pm SD & \\
\hline
\end{tabular}

SD - Standard Deviation; BMI - Body Mass Index. 
The prevalence of associated comorbidities is higher among females in this study (Table 2).

Table 2. Description of the comorbidities associated with obesity in the preoperative period of OAGB.

\begin{tabular}{ccccc} 
Morbidities & \multicolumn{2}{c}{ Male (n= 67) } & \multicolumn{2}{c}{ Female $(\mathbf{n}=\mathbf{2 8 4})$} \\
\cline { 2 - 5 } SAH & Sim & Não & Sim & Não \\
& $12.25 \%$ & $6.84 \%$ & $43.02 \%$ & $37.89 \%$ \\
T2DM & & & & \\
Dyslipidemia & $6.27 \%$ & $12.82 \%$ & $18.23 \%$ & $62.68 \%$ \\
& $11.11 \%$ & $7.98 \%$ & $47.29 \%$ & $33.62 \%$ \\
\hline
\end{tabular}

SAH - Systemic Arterial Hypertension; DM2 - Diabetes Mellitus 2; Generalized Estimating Equations $(\%)$.

A reduction in the \% EWL can be observed in the 351 evaluated patients and in the analysis of the variables glycated hemoglobin (HbA1c), glucose, and CVR. It was observed that all patients reduced showed weight (73.2\%), and decreased $\mathrm{Hb} 1 \mathrm{Ac}(\mathrm{p}=$ $0.000)$ and glucose (0.000) in groups one and two within 24 months, minimizing the CVR for $\mathrm{G} 2(\geq 70 \%)(\mathrm{p}=0.045)$ in the postoperative period. When comparing the analysis of variations between T2-T3 (6-12 months), only G1 reduced Hb1Ac $(\mathrm{p}=0.025)$ and decreased the CVR $(p=0.001)$. There was no difference between the two groups at T3T4 (12-18 months). There was a significant reduction in the glucose level in G1 $<70 \%$ (p $=0.036)$ at $\mathrm{T} 4-\mathrm{T} 5$ (18-24 months).

Graph 1 shows the variation in the levels of glycated hemoglobin $(\mathrm{HbA} 1 \mathrm{c})$ in patients in G1 $(<70 \%$ EWL) and G2 $(\geq 70 \%$ EWL) during the two years after bariatric surgery. It was found that all patients were overweight and had altered glycated hemoglobin $(\mathrm{HbA} 1 \mathrm{c})(5.7-7 \%)$ in the preoperative period $(\mathrm{T} 1)$. There was a reduction in weight and HbA1c in both groups with a statistically significant difference $(p=0.000)$ after the procedure in T2 (6 months) and T3 (12 months). On the other hand, the group that lost less weight (G2) showed a reduction of $\mathrm{Hb} 1 \mathrm{Ac}$ up to $\mathrm{T} 3$ (12 months) and a stability from 
T4 (18 months), which remained up to T5 (24 months). Patients who lost more weight (12) maintained a similar behavior to G1 up to T3 (12 months). After 12 months, they showed a significant increase in Hb1Ac until T5 (24 months).

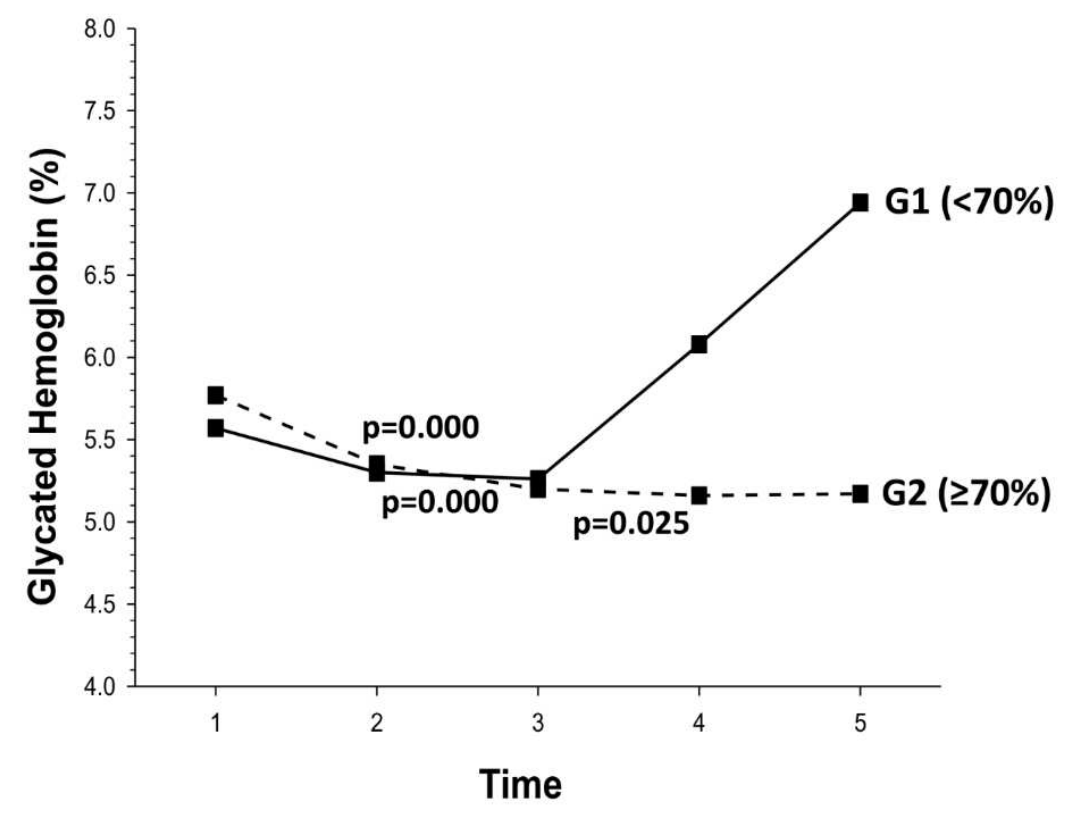

Graph 1: Link between glycated hemoglobin, time of surgery and percentage of weightloss (\%) - Hb1 Ac / Time $/ \%$ EWL.

Graph 2 shows the variation in Glucose levels in patients in G1 (<70\% EWL) and G2 (>70\% EWL) during the two years after bariatric surgery. In this analysis, it was found that all patients were overweight and had impaired glucose $(>100 \mathrm{mg} / \mathrm{dL})$ in the preoperative period (T1). After the procedure in $\mathrm{T} 2$ (6 months), there was a reduction in weight and glucose in both groups with a statistically significant difference $(p=0.000)$, with similar global behavior in both groups (G1 and G2), up to T4 (18 months). However, from T4 (18 months) to T5 (24 months), patients who lost more than 70\% EWL (G2) reduced glucose $(\mathrm{T} 4=82.1-64.7 \mathrm{mg} / \mathrm{dL}$ and $\mathrm{T} 5=82.5-78.6 \mathrm{mg} / \mathrm{dL})$, showing higher 
stability up to T5. Patients who lost less weight (G1) had a significant drop in glucose at 18 months $/ 24$ months $(\mathrm{p}=0.036)$.

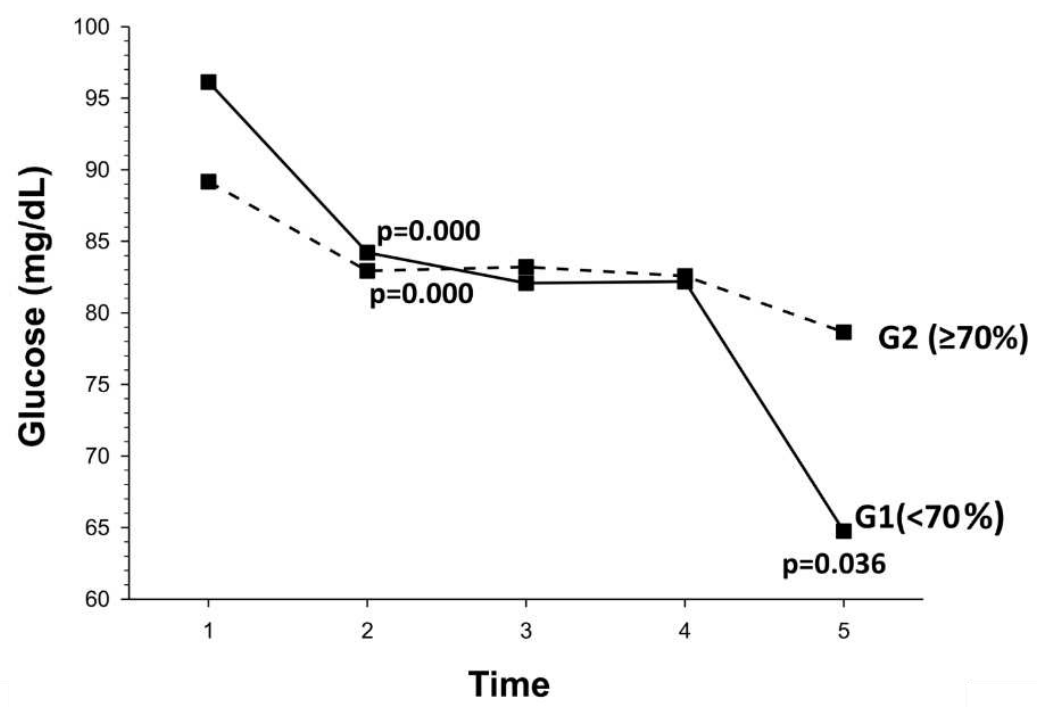

Graph 2: Link between glucose, time of surgery and percentage of weight loss (\%) - Glucose / Time $/ \%$ EWL.

Graph 3 shows the variable of the probability of a cardiovascular event in the next 10 years, which was represented here by CVR in groups G1 $(<70 \%)$ and G2 $(\geq 70 \%)$, during two years after bariatric surgery. During this period, it was found that all patients had a high risk of cardiovascular complications (31\%) in the preoperative period (T1). Six months after surgery (T2), there was a reduction in cardiovascular risks with the loss of excess weight and a reduction in metabolic rates (Glucose and HbA1c) in both groups (G1 and G2). However, the group that showed a statistically significant difference was G2 with a reduction in CVR at T2 $(\mathrm{p}=0.045)$ and $\mathrm{T} 3(\mathrm{p}=0.001)$, justifying the decrease in glucose and $\mathrm{Hb} 1 \mathrm{Ac}$ with excess weight. At other times (T), patients did not show a statistically significant difference. 


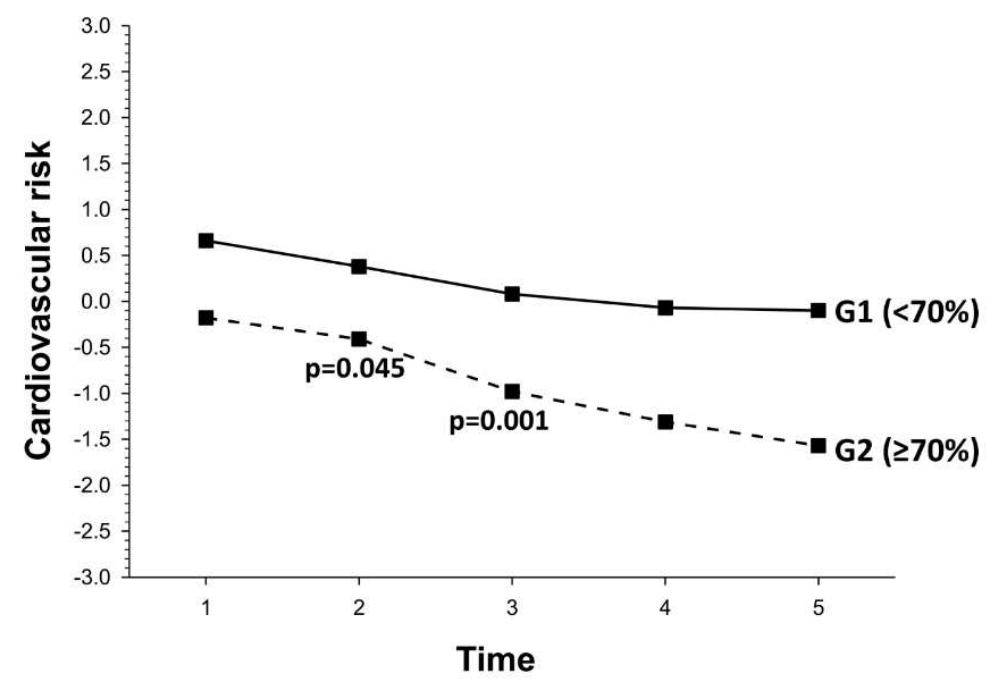

Graph 3: Link between cardiovascular risk, time of surgeryand percentage weight loss (\%) - CVR/ Time/ $\%$ EWL.

\section{Discussion}

The analyses of preoperative comorbidities have shown that 291 patients $(82.9 \%)$ had some morbidity. Thus, obesity is a clinical condition that forms a risk factor for other diseases. The most common comorbidities were hypertension (55.27\%), T2DM (24.5\%) and dyslipidemia (58.4\%). These data were also found in other studies [31-34]. SanchesSantos and collaborators [35] highlighted that $85.7 \%$ of 50 patients achieved improvement in comorbidities associated with obesity five years after Roux-en-Y gastric bypass. Most patients undergoing bariatric surgery in this study were female (80.9\%), which confirms the results of other studies carried out in different regions of the country $[2,13,21]$. Unlike women, men $(19.1 \%)$ tend to seek this possibility of BS only when their daily physical activities are compromised [24]. According to Sandoval [20], clinical treatment in morbidly obese individuals results in a reduction of only $5-10 \%$ of body weight (rarely maintained), whereas gastric bypass determines a weight reduction of around $50 \%$, with results maintained in the long-term. By analyzing the link between 
bariatric surgery and the impact on excess weight loss, it is noticed that bariatric surgery has been proven to be quite effective [32-35], with the mean pre-surgical BMI being 42.6 $\mathrm{kg} / \mathrm{m}^{2} \pm 4.65$ and the post-surgical being $26.7 \mathrm{~kg} / \mathrm{m}^{2} \pm 4.5$. Patients reduced around the $\%$ EWL $( \pm 70 \%)$, which implies a significant reduction in cardiovascular mortality as well as mortality from all causes associated with excessive weight. Similar data have been reported by other authors such as Costa et al., [28] who found satisfactory \% EWL (\% EWL $>50 \%)$ in $94.7 \%$ of the analyzed patients. Glycated hemoglobin in G2 $(\geq 70 \%)$ showed a reduction up to 12 months and stability from 18 to 24 months. Patients who lost more weight $(\mathrm{G} 1=<70 \%)$ maintained a similar behavior of $\mathrm{Hb} 1 \mathrm{Ac}$ up to 12 months. Schauer and collaborators [37] found a reduction of $(-2.9 \pm 1.6 \%)$ in glycated hemoglobin in 12 months of follow-up. Other authors [38,36] also found similar values of Hb1Ac 24 months after the intervention in studies with similar populations. A significant increase in Hb1Ac was observed after 18 months and up to 24 months. The increase in glycated hemoglobin from T2 (12 months) to T5 (24 months) in this study can be justified because the higher the value of fasting glycemia in the patient, the higher the value of glycated hemoglobin ( $\mathrm{Hb} 1 \mathrm{Ac})$, showing the existing relationship between these two parameters. A decrease in glucose after T4 (18 months) was observed and is shown in Graph 2. It is observed that glycemic control is an alteration that occurs quickly after the surgical intervention and is maintained over the long-term. Other authors [13,22,23,26,30] also highlighted the results found in this study. Studies with longer follow-up showed higher percentages of patients with normal blood glucose values [27,29]. After 6 months of follow-up, Parikh [41] found $65 \%$ of patients with $\mathrm{HbA1c}<6 \%$; at 12 months, Shauer et al. [37] observed that $42 \%$ of their patients had these results; at 18 months and Kashyap et al. [39] found an $80 \%$ diabetes remission rate; and Hsu and collaborators [40] obtained a rate of $53 \%$ of individuals with normal glycemic control after 5 years, which is 
considered prolonged remission. It was observed that with a longer follow-up, glucose decreased to $64.7 \mathrm{mg} / \mathrm{dL}$ at 24 months postoperatively and $\mathrm{Hb} 1 \mathrm{Ac}$ at 6 months postoperatively was already $5.5 \%$ in this study. Regarding CVR, it was found that in the preoperative period (T1), all patients had a $31 \%$ probability of cardiovascular problems within 10 years, which was considered a high risk of cardiovascular complications. There was a reduction in cardiovascular risks with weight loss and a reduction in metabolic rates (glucose and HbA1c) after 6 months of surgery (T2) in both groups (G1 and G2). However, the group that showed a statistically significant difference was G1 with a reduction in CVR at $\mathrm{T} 2(\mathrm{p}=0.045)$ and $\mathrm{T} 3(\mathrm{p}=0.001)$, explaining the decrease in glucose and $\mathrm{Hb} 1 \mathrm{Ac}$ with weight loss. Patients did not show a statistically significant difference at other times. The weight loss obtained within 24 months (73.2\%) was similar to that found by Ferraz et al. [43] (78\%). Other studies have found a reduction of 59.2\% EWL and 64\% EWL in the same period of time $[36,42]$. Rapid weight loss in the first six months and up to 24 months is an important factor in reducing the metabolic and lipid profile, in addition to being important for reducing risk factors for cardiovascular diseases. However, there was a slight correlation between weight loss and CVR after six months, which is maintained up to 24 months of the surgery. Garcia-Diaz et al. [44] reported the impact of gastroplasty on the reduction of excess body weight and on the control of cardiovascular risk factors (CVRFs) one to three years after surgery, considering this period most relevant clinically. Within that period, a reduction of 20 to $50 \mathrm{~kg}$ in body weight is expected, around $35 \%$ in BMI and the resolution of systemic arterial hypertension (SAH), type 2 diabetes mellitus (T2DM) and dyslipidemia in 62\%,76\% and $70 \%$ of individuals, respectively $[12,24,25,26]$. This study has shown that the expected and described results have already been observed at the end of the sixth month after gastroplasty and they remain at the end of the 24 months in both groups surveyed. When evaluating the effect 
of excess weight loss on the reduction of CVR and the control of T2DM, it can be said that bariatric surgery has been efficient in controlling the parameters evaluated in this study.

\section{Method}

This is a retrospective, descriptive and cross-sectional study with a quantitative approach carried out in an Obesity and Digestive Surgery Clinic located in an inland city in the state of Rio Grande do Sul - Brazil, which performs an average of 50 bariatric surgeries per month. The development of this study took place in accordance with ethical rules and was approved by the Research Ethics Committee of Franciscan University (UFN); the approval is registered under number 3.093.324. Data collection was carried out by analyzing the clinic's database of patients. Data were collected from March 2018 to March 2019 and were analyzed using the medical records of patients who underwent bariatric surgery from March 2014 to March 2016. The sample consisted of adults of both genders, aged over 18, who had undergone bariatric surgery at least two years ago. The Framinghan Heart Study Score [16] was used in order to establish the Cardiovascular Risk. Framingham is a cohort study that has been active since 1948. The Framinghan Score assesses the likelihood of a cardiovascular event such as a heart attack or stroke in the next 10 years. The probability of these cardiovascular accidents is expressed in terms of the degree of risk: low, moderate and high. In order to assess the risk (calculation), the following parameters are used: age, blood pressure, LDLc, HDLc, smoking (yes or no) and Diabetes Mellitus (yes or no). Cardiovascular risk factors can be classified as nonmodifiable, such as age, gender and heredity, or modifiable, such as obesity, dyslipidemia, diabetes, sedentary lifestyle, smoking, high blood pressure, stress and inadequate diet. All data were collected from the patients' medical records. The following 
data were obtained from patients' medical records in addition to the data mentioned above: a) weight and height, to calculate BMI, classifying according to the World Health Organization (WHO) (2017) [17]; b) personal data such as age and gender; c) presence of associated morbidities (systemic arterial hypertension - SAH, diabetes mellitus type 2 - T2DM, metabolic syndrome - MS, dyslipidemia and cardiovascular risk - CVR); and d) biochemical parameters (HDLc and LDLc, triglycerides, glucose, glycated hemoglob in - (Hb1Ac). All of these data were collected in the pre-surgical and post-surgical periods $(6,12,18$ and 24 months). In order to calculate the $\%$ of excess weight loss (\% EWL), the following formula was used:

\section{preoperative weight $[\mathrm{kg}]$ - current weight $[\mathrm{kg}]$ \\ preoperative weight $[\mathrm{kg}]$ - ideal weight* \\ (BMI $25 \mathrm{~kg} / \mathrm{m}^{2}$ x Height) *.}

They were categorized in G1 with weight loss $<70 \%$ EWL and G2 with weight loss $\geq 70 \%$ EWL according to Deitel and Shikora [18].

\section{Statistical Analysis}

The data were inserted into the Microsoft Excel 2010® program and, double-checked and transferred to the IBM SPSS ${ }^{\circledR}$ program (Statistical Package for Social Science), version 20.0. The results were considered statistically significant at $\mathrm{p}<0.05$ for all statistical data. The analyses of the quantitative data were described by average and standard deviations. The median and interquartile range were used in the breakdown of distributional assumptions. Categorical data were described by counts and percentages. The analysis of longitudinal variability of the quantitative medians (glucose, CVR, Hb1Ac) was evaluated by using Generalized Estimation Equations, taking the interaction model between the two groups as factors: G1 $(<70 \%)$ and G2 $(\geq 70 \%)$. 


\section{Conclusion}

Based on the results presented in this study, it is possible to conclude that there was a positive impact determined by gastric bypass on the loss of excess weight (EWL) and a reduction of the biochemical parameters related to glucose metabolism and CVRF; they are extremely significant after six months of surgery and maintained after 24 months, which indicates that bariatric surgery is effective in losing weight with an improvement in anthropometric, metabolic and biochemical parameters and in reducing morbidities associated with obesity.

\section{References}

1. WOH - The Asia-Pacific perspective: Redefining obesity and its treatment. World Health Organization - Western Pacific Region. International Association for the Study of Obesity. Geneve: World Health Organization. (2018).

2. I Diretriz Brasileira de Diagnóstico e Tratamento da Síndrome Metabólica. Arq. Bras. Card. 84, 1-28 (2018).

3. Diretrizes Associação Médica Brasileira e Conselho Federal de Medicina. Sobrepeso e obesidade; diagnóstico. Brasîlia (DF): Soc. Bras. Endocrinol. Metab. (2016).

4. Sjöström, L. et al. Effects of bariatric surgery on mortality in Swedish obese subjects. N. Engl. J. Med. 8 (357), 741-53 (2007).

5. Santos, AX. Prevalência de Hipertensão Arterial sistêmica e Diabetes Mellitus em obesos Candidatos à cirurgia bariátrica. Rev. Bras. Obes. Nut. Emag. 34, 184-190 (2012).

6. Bastos, E.C.L. et al. Fatores determinantes do reganho ponderal no pós-operatório de cirurgia bariátrica. Arq. Bras. Cir. Dig. 26, 1-8 (2013).

7. Aron-Wisnewsky. J. et al. The advanced- DiaRem score improves prediction of diabetes remission 1 year post-Roux-en-Y gastric bypass. Diab. 10 (60), 182-902 (2017). 
8. Pimenta, G.P. et al. Avaliação da qualidade de vida tardia após gastroplastia vertical. Rev. Col. Bras. Cir. 6 (40), 453-457 (2013).

9. Bordalo, L.A., Mourão, D.M., Bressan, J. Deficiências Nutricionais após cirurgia bariátrica: Por que ocorrem? Act. Med. Port. 4 (24), 1021-28 (2011).

10. Carlsson, L.M.S. et al. Long-term incidence of microvascular disease after bariatric surgery or usual care in patients with obesity, stratified by baseline glycaemic status: apost-hoc analysis of participants from the Swedish Obese Subjects Study. Lancet: Diab. Endocrinol. 4 (5), 271-9 (2017).

11. Costa, T.M.R.L. et al. Impacto da deficiência nutricional na massa óssea após a cirurgia bariátrica. Arq. Bras. Cir. Dig. 29, 1-4 (2016).

12. Buchwald, H. et al. Bariatric surgery: a systematic review and meta-analysis. JAMA. 292, 1724-37 (2004).

13. Dicker, D. et al. Prediction of longterm diabetes remission after RYGB, sleeve gastrectomy, and adjustable gastric banding using DiaRem and advanced-DiaRem scores. Obes. Surg. 3 (29), 796-804 (2019).

14. Sjöström, L. et al. Association of bariatric surgery with long-term remission of type 2 diabetes and with microvascular and macrovascular complications. JAMA. 22 (311), 2297-304, (2014).

15. Kelles, S.M.B. et al. Perfil de pacientes submetidos à cirurgia bariátrica, assistidos pelo Sistema Único de Saúde do Brasil: revisão sistemática. Cad. Saúde Púb. 31, 8-16 (2015).

16. Framingham Heart Study. Disponível em: www.framinghamheartstudy.org. (2008).

17. WHO - World Hearth Organization. Physical status: the use and interpretation of anthropometry. Geneva (2017).

18. Deitel, M. \& Shikora, S.A. The development of the surgical treatment of morbid obesity. J Am Coll of Nutrition. 5 (21), 365-71 (2014). 
19. Pucci, A. et al. Type 2 diabetes remission 2 years post Roux-en-Y gastric bypass and sleeve gastrectomy: the role of the weight loss and comparison of DiaRem and DiaBetter scores. Diabet. Med. 3 (35), 360-7, (2018).

20. Brasil. Ministério da Saúde. Secretária de Vigilância em Saúde. Plano de ações estratégicas para o enfrentamento das doenças crônicas não transmissíveis (DCNT) no Brasil 2011-2022/ Ministério da Saúde (2019).

21. Still, C.D. et al. Preoperative prediction of type 2 diabetes remission after Roux-enY gastric bypass surgery: a retrospective cohort study. Lancet Diab. Endocrinol. 2 (1), 38-45, (2014).

22. Oliveira, D.M., Meregui, M.A.B. \& Jesus, M.C.P. A decisão da mulher obesa pela cirurgia bariátrica à luz da fenomenologia social. Rev. Esc. Enferm USP. 6 (48), 970-6 (2014).

23. Mariano, M.L.L. et al. Cirurgia bariátrica: repercussões na sexualidade da pessoa obesa. Rev. Col. Bras. Cir. 6 (41), 412-20 (2014).

24. Honarmand, K. et al. Type 2 diabetes remission rates 1-year post-Roux-en-Y gastric bypass and validation of the DiaRem score: the Ontario Bariatric Network experience. Clin. Obes. 7 (3), 176-82 (2017).

25. Coleman, K.J. et al. Long-termmicrovascular disease outcomes in patients with type 2 diabetes after bariatric surgery: evidence for the legacy effect of surgery. Diab. Care. 8 (39), 1400-7 (2016).

26. Shen, S.C. et al. Validating risk prediction models of diabetes remission after sleeve gastrectomy. Obes. Surg. 1 (29), 221-9 (2019).

27. Wood, G.C. et al. Association ofDiaRem score with cure of type 2 diabetes following bariatric surgery. JAMA. 151 (8), 779-81 (2016). 
28. Sjöholm, K. et al. Weight changeadjusted effects of gastric bypass surgery on glucose metabolism: 2- and 10-year results from the Swedish Obese Subjects (SOS) Study. Diab. Care. 4 394), 625-31 (2016).

29. Debédat, J. et al. Long-term relapse of type 2 diabetes after Roux-en-Y gastric bypass: prediction and clinical relevance. Diab. Care. 10 (41), 2086-95 (2018).

30. Diretrizes Associação Médica Brasileira e Conselho Federal de Medicina. Sobrepeso e obesidade; diagnóstico. Brasîlia (DF): Soc. Bras. Endoc. Metab. (2018).

31. Monteiro. Jr., F.C. et al. Efeito da perda ponderal induzida pela cirurgia bariátrica sobre a prevalência de síndrome metabólica. Arq. Bras. Card. 92, 452-6 (2009).

32. Aminian, A. et al. Individualized metabolic surgery score: procedure selection based on diabetes severity. Ann. Surg. 4 (266), 650-7 (2017).

33. Costa, R.C. et al. Outcomes on quality of life, weight loss, and comorbidities after Roux-en-Y gastric bypass. Arq. Gastroent. 3 (51), 165-70 (2014).

34. Prevedello, C.F., Colpo, E., Mayer, E.T., Copetti, H. Análise do impacto da cirurgia bariátrica em uma população do centro do estado do Rio Grande do Sul utilizando o método BAROS. Arq. Gastroent. 3 (46), 199-203 (2009).

35. Wood, G.C. et al. Performance of the DiaRem score for predicting diabetes remission in two health systems following bariatric surgery procedures in Hispanic and nonHispanic White patients. Obes. Surg. 1 (281), 61-8 (2018).

36. Brethauer, S.A. et al. Can diabetes be surgically cured? Long-term metabolic effects of bariatric surgery in obese patients with type 2 diabetes mellitus. Ann. Surg. 4 (258), 628-36 (2013).

37. Koliaki, C. et al. The role of bariatric surgery to treat diabetes: current challenges and perspectives. BMC Endocr. Disord. 1 (17), 50-4 (2017).

38. Schauer, P.R. et al. Outcomes after laparoscopic Rouxen-Y gastric bypass for morbid obesity. Ann. Surg. 4 (232), 515-29 (2010). 
39. Sanchez-Santos, R. et al. Longterm health-related quality of life following gastric bypass: Influence of depression. Obes. Surg. 5 (16), 580-5 (2010).

40. Silva-Neto, E.F. et al. Cirurgia bariátrica reverte risco metabólico em pacientes assistidos em nível ambulatorial. Arq. Bras. Cir. Dig. 1 (27), 38-42 (2014).

41. Carvalho, P.S. et al. Cirurgia bariátrica cura síndrome metabólica? Arq. Bras. Endoc. Metab. 1 (51), 9-85 (2010).

42. Schauer, P.R. et al. Bariatric surgery versus intensive medical therapy for diabetes-3-year outcomes. N. England. J. Med. 21 (370), 2012-13 (2014).

43. Mingrone, G. et al. Bariatric surgery versus conventional medical therapy for type 2 diabetes. N. England. Med. 17 (366), 1577-85 (2012).

44. Kashyap, S.R. et al. Metabolic effects of bariatric surgery in patients with moderate obesity and type 2 diabetes: analysis of a randomized control trial comparing surgery with intensive medical treatment. Diab. Care. 8 (36), 2175-82 (2013).

45. Hsu, C.C. et al. Effect of bariatric surgery vs medical treatment on type 2 diabetes in patients with body mass index lower than 35 five-year outcome. JAMA. 2 (150), 1117-24 (2015).

46. Parikh, M. et al. Randomized pilot trial of bariatric surgery versus intensive medical weight management on diabetes remission in type 2 diabetic patients who do NOT meet NIH criteria for surgery and the role of soluble RAGE as a novel biomarker of success. Ann. Surg.4 (260), 617-22 (2014).

47. Nathan, D.M. Long-term complications of diabetes mellitus. N. Engl. J. Med. 23 (328), 1676 (1993).

48. Brethauer, S.A. et al. Can diabetes be surgically cured? Long-term metabolic effects of bariatric surgery in obese patients with type 2 diabetes mellitus. Ann. Surg. 4 (258), 628-36 (2013).

49. Andriolo, A. \& Sumit, N. M. Importância da determinação da hemoglobina glicada no monitoramento do paciente portador de diabetes mellitus. J. Bras. Patolog. Med. Lab. 3 (42), 22-28 (2006). 
50. Carlsson, L.M. et al. , Peltonen M, Ahlin S, et al. Bariatric surgery and prevention of type 2 diabetes in Swedish obese subjects. N. Engl. J. Med. 8 (367), 695-704 (2012).

51. Aminian, A. et al. Late relapse of diabetes after bariatric surgery: not rare, but not a failure. Diab. Care. 3 (43), 534-40 (2020).

52. Ballantyne, G.H., Wasielewski, A. \& Saunders, J.K. The Surgical Treatment of Type II Diabetes Mellitus: Changes in HOMA Insulin Resistance in the First Year Following Laparoscopic Roux-en-Y Gastric Bypass (LRYGB) and Laparoscopic Adjustable Gastric Banding (LAGB). Obes. Surg. 19, 1297-1303 (2016).

53. Ferraz, E.M. et al. Tratamento cirúrgico da obesidade mórbida. Rev. Col. Bras. Cir. 2 (30), 98-105 (2015).

54. Garcia-Diaz, J.D. et al. Changes in lipid profile after biliopancreatic diversion. Obes. Surg. 5 (13), 756-760 (2015).

55. Pujante, P. et al. Modification of cardiometabolic profile in obese diabetic patients after bariatric surgery: changes in cardiovascular risk. Rev. Esp. Card. 66, 812-818 (2013).

56. Goday, A. et al. Can bariatric surgery improve cardiovascular risk factors in the metabolically healthy but morbidly obese patient? Surg. Obes. Relat. Diords. 10, 871876 (2014).

57. Vila, M. et al. Changes in lipid profile and insulin resistance in obese patients after Scopinaro biliopancreatic diversion. Obes. Surg. 3 (19), 299-306 (2017).

\section{Author contributions}

Study concepts: F.F.P. and C.M.B.M. Study design: F.F.P. and C.M.B.M. Data acquisition: F.F.P., L.D.P., L.O.L and C.M.B.M. Quality control of data and algorithms: F.F.P. and C.M.B.M. Data analysis and interpretation: F.F.P. and C.M.B.M. Manuscript preparation: F.F.P. Manuscript editing F.F.P. Manuscript review: F.F.P. and C.M.B.M. Statistical analysis: F.F.P., G.C.A., L.D.P., A.C.A.M., L, O.L., D.S.M., A.C. and C.M.B.M. and C.M.B.M. K.Y., S.I., and T.Y. Manuscript preparation: K.Y. and S.I. Manuscript editing: K.Y., S.I., and T.Y. Manuscript review: T.Y., Y.O., and M.M. 


\section{Funding}

This study did not obtain funding for the research and the decision to submit the manuscript for publication.

\section{Competing interests}

The authors declare no competing interests.

Correspondence and requests for materials should be addressed to F.F.P. (flapedron@gmail.com).

Ethics: Data collection was performed from patients' medical records in studies involving human participants. They were in accordance with the ethical standards of the institutional and/or national research committee and the 1964 Helsinki Declaration and its amendments or comparable ethical standards.

Informed Consent: Informed consent was obtained from all individual participants included in the study.

Consent to publish: I authorize the publication of the manuscript. 
Figures

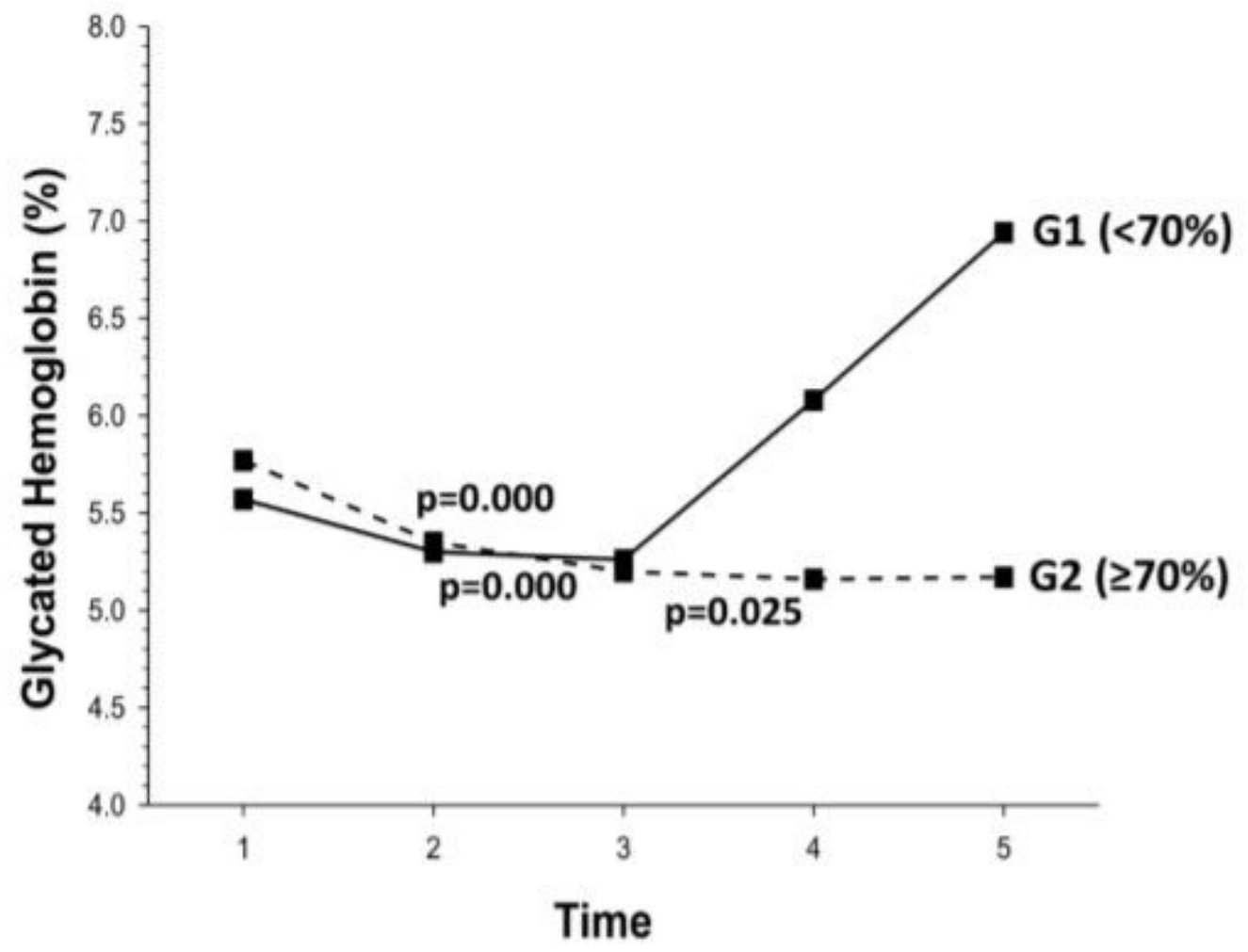

\section{Figure 1}

Graph 1: Link between glycated hemoglobin, time of surgery and percentage of weight loss (\%) - Hb1 Ac / Time /\% EWL. 


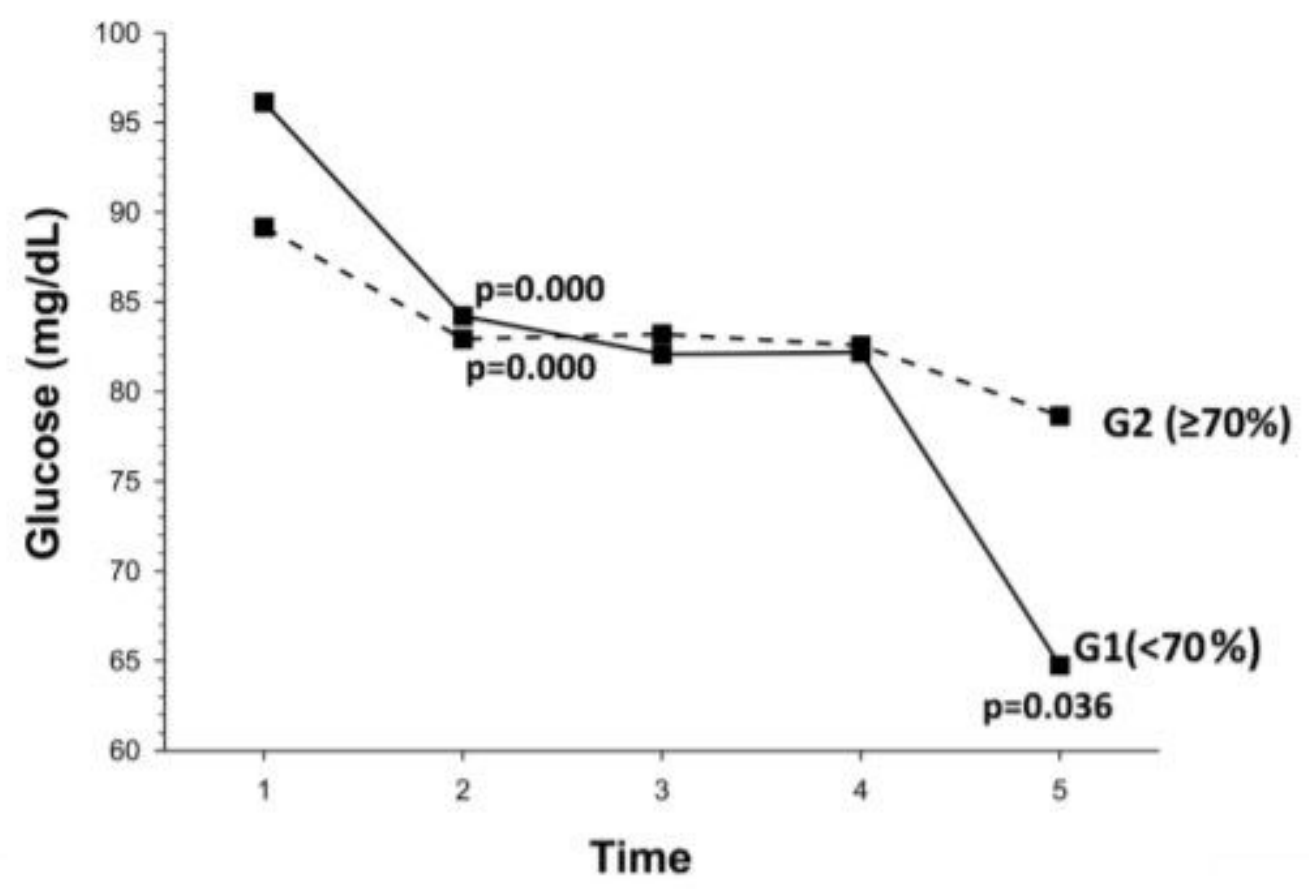

Figure 2

Graph 2: Link between glucose, time of surgery and percentage of weight loss (\%) - Glucose / Time /\% EWL.

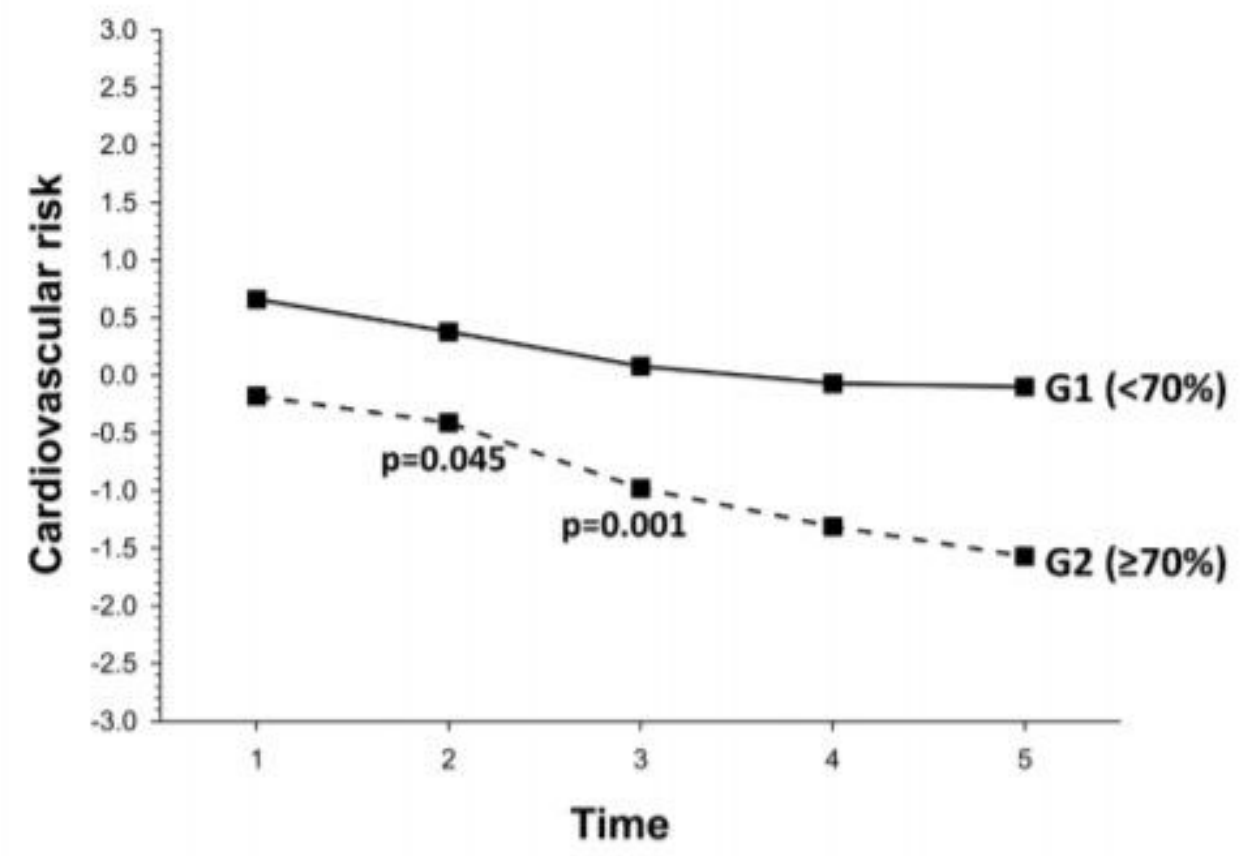

Figure 3 
Graph 3: Link between cardiovascular risk, time of surgery and percentage weight loss (\%) - CVR/ Time/ $\%$ EWL. 